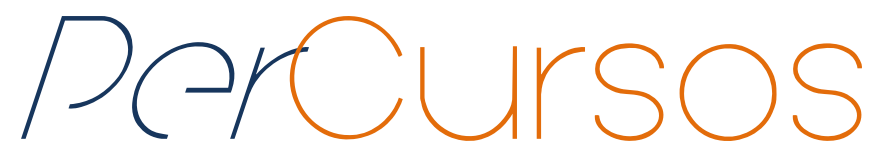

\title{
Centralidade e a cidade contemporânea: reflexões para pensar o direito à cidade na produção da metrópole ${ }^{1}$
}

\begin{abstract}
Resumo
A centralidade é tida como um processo que exprime a essência básica do fenômeno urbano, do qual não pode ser dissociado, reunindo em simultaneidade todas as possibilidades de interação social, além de ser um elemento que possui grande potencial estruturador do espaço. Entretanto, suas manifestações espaciais contemporâneas indicam a alteração da tradicional hierarquia de um centro único polarizador para a consolidação de tendências policêntricas, manifestadas em redes hierárquicas e complementares de centros e subcentros que avançam em escala metropolitana. Em meio a esse contexto, a maneira como alguns dos novos espaços dotados de centralidade se expressam sob o domínio e a lógica capitalistas, buscando conformar áreas homogeneizadas e, ao mesmo tempo, fragmentando o espaço urbano, nega a centralidade a grandes setores da população e tende a aprofundar a desigualdade socioespacial. Por esse motivo, indica-se como imperativa uma ressignificação do tema, uma vez que a luta pelo direito à cidade passa a se associar ao direito à centralidade, inequívoca e completa, que poderá, pelo confronto e não pela separação entre as diferenças, levar a uma cidade possível de ser apropriada por todos.
\end{abstract}

Palavras-chave: Centralidade. Produção do Espaço. Metrópole. Direito à Cidade.

\section{Gustavo Domingues Gaspari}

Arquiteto e Urbanista pela

Universidade Federal do Paraná.

Mestrando em Planejamento

Urbano pela Universidade

Federal do Paraná. Aluno bolsista

CAPES/Fundação Araucária.

gasparigd@gmail.com

\section{Madianita Nunes da Silva}

Arquiteta e Urbanista e Doutora em Geografia pela Universidade Federal do Paraná. Docente do

Curso de Graduação em

Arquitetura e Urbanismo e do

Programa de Pós-Graduação em

Planejamento Urbano da

Universidade Federal do Paraná. madianita@gmail.com

\section{Para citar este artigo:}

GASPARI, Gustavo Domingues; DA SILVA, Madianita Nunes. Centralidade e a cidade contemporânea: reflexões para pensar o direito à cidade na produção da metrópole. Revista PerCursos, Florianópolis, v. 19, n.40, p. 67 - 37, jan./abr. 2018.

\section{DOI: $10.5965 / 1984724619392018005$}

http://dx.doi.org/10.5965/1984724619392018005

\footnotetext{
${ }^{1}$ O presente trabalho foi realizado com apoio da Coordenação de Aperfeiçoamento de Pessoal de Nível Superior - Brasil (CAPES) - Código de Financiamento 001
} 


\title{
Centrality and the contemporary city: considerations to think about the right to the city in the production of the metropolis
}

\begin{abstract}
Centrality is understood as a process that expresses the basic meaning of the urban phenomenon, from which it can't be apart, simultaneously gathering all the possibilities of social interactions, besides being an element of great spatial structuring potential. However, its contemporary spatial expressions points to changes on the traditional hierarchy composed only by one main center towards the consolidation of polycentric tendencies, expressed by hierarchically and complimentary centers and subcenters grids that expands onto the metropolitan scale. In the midst of this context, the way in which some of the new spaces endowed with centrality are expressed under capitalistic domain and logic, seeking to homogenize and, at the same time, to fragment the urban space, denies the centrality to large sectors of the population, tending to increase socioespatial inequality. Due to this reason, it is necessary do re-signify the theme, considering that the struggle for the right to the city associated to the right to centrality, in its unambiguous and complete meaning, can lead, by the confrontation of inequalities instead of its segregation, to a appropriable city for all.
\end{abstract}

Keywords: Centrality. Production of Space. Metropolitan Dynamics. Right to the City. 


\section{Introdução}

O objetivo do artigo é realizar uma reflexão a respeito da centralidade urbana, enquanto processo e conceito, e seu significado para a produção do espaço na cidade contemporânea. É proposta a construção de um entendimento que auxilie no avanço da compreensão do papel exercido pela centralidade nos novos paradigmas de produção do espaço urbano e nas lutas pelo direito à cidade.

Primeiramente, é realizada uma caracterização do espaço urbano e seu processo dialético de produção pela sociedade, a partir do qual se destaca a importância da centralidade como fenômeno, e sua relação com o padrão de estruturação do espaço nas cidades brasileiras. Em seguida, analisam-se processos e espacialidades que traduzem as novas formas de expressão da centralidade na cidade contemporânea, colaborando para uma ressignificação do conceito e para a compreensão de sua apropriação pelo capital como estratégia de reprodução. Por último, são tecidas considerações sobre o papel que a centralidade pode desempenhar nas lutas sociais de resistência à opressão da lógica de consumo e da prevalência do valor de troca sobre o cotidiano das classes populares, a partir das quais se defende que, à possibilidade de acesso ao "direito à cidade" está intimamente ligado o "direito à centralidade".

\section{A centralidade como essência e elemento estruturador do urbano}

Para discutir a importância da centralidade e de suas formas de expressão na estruturação da cidade é importante estabelecer, em primeiro lugar, o caráter do espaço em que este fenômeno se expressa, o espaço urbano. Nos termos de Corrêa (1989), o espaço urbano é, simultaneamente, condição, meio e produto das ações sociais através do tempo e, por isso, tanto forma a sociedade quanto por ela é formado. Lefebvre evidencia a importância do papel do urbano nesse sentido, como elemento agregador da sociedade que permite o estabelecimento de suas relações sociais e que, ao mesmo tempo, são imprescindíveis à própria existência da cidade: 
A cidade atrai para si tudo o que nasce, da natureza e do trabalho, noutros lugares: frutos e objetos, produtos e produtores, obras e criações, atividades e situações. O que ela cria? Nada. Ela centraliza as criações. E, no entanto, ela cria tudo. Nada existe sem troca, sem aproximação, sem proximidade, isto é, sem relações. (LEFEBVRE, 1999, p. 111)

Em segundo lugar, o espaço urbano é estruturado, ou seja, não está organizado ao acaso, e os processos sociais a ele relacionados exprimem as especificidades de cada tipo e período da organização social (CASTELLS, 1983). Como resultado disso, o espaço urbano reúne e acumula diferentes funções ao longo do tempo e da lógica dominante de produção da cidade em cada uma das fases da sociedade (LEFEBVRE, 1999). Não obstante, destaca-se que a continuidade e o dinamismo dos processos sociais que formam o urbano impedem que se fale de uma "estrutura urbana" como objeto de análise, adotando-se em seu lugar "o uso da expressão estruturação para garantir a passagem da ideia de que esta organização/desorganização da cidade contém a dinâmica do próprio processo social que a determina" (SPOSITO, 1991, p. 6, grifo no original). Nesse sentido, Villaça (2001, p. 327) define a estrutura urbana "enquanto um todo articulado de partes que se relacionam, no qual alterações em uma parte, ou em uma relação, acarretam alterações nas demais partes e relações", ou seja, cujo caráter dinâmico a torna passível de contínua reestruturação.

Nessa dinâmica contínua de estruturação urbana, o par centralizaçãodescentralização, responsável pela formação das áreas de centralidade, instaura-se como um processo de destaque, por conter a essência do fenômeno urbano, conduzindo a estruturação do espaço a partir de sua natureza dialética e contraditória:

Esse espaço urbano é contradição concreta. O estudo de sua lógica e de suas propriedades formais conduz à análise dialética de suas contradições. O centro urbano é preenchido até sua saturação; ele apodrece ou explode. Ás vezes, invertendo seu sentido, ele organiza em torno de si o vazio, a raridade. (LEFEBVRE, 1999, p. 46) 
Daí entende-se o poder estruturador que os espaços dotados de centralidade possuem, ao organizarem tanto seu próprio espaço quanto os espaços ao redor de si, produzindo, ao mesmo tempo, dois resultados: o centro e o não-centro (VILLAÇA, 2001). No contexto da urbanização brasileira, o padrão de urbanização centro-periferia que caracterizou o desenvolvimento inicial das metrópoles e grandes cidades é uma expressão deste processo. Enquanto o centro foi apropriado pelas camadas de alta renda, a periferia, composta em grande parcela pela moradia das classes de baixa renda, além de não ser dotada das mesmas atividades e infraestrutura da área central, foi marcada por sua limitada acessibilidade, produzindo uma cidade marcada pela desigualdade de acesso aos benefícios da urbanização por parte de sua população, em prejuízo ao direito à cidade.

Entretanto, o centro não possui um caráter fixo como ponto geográfico, uma vez que, conforme Villaça (2001, p. 238), "nenhuma área é ou não é centro; como fruto de um processo - movimento (dialético) - torna-se centro. No social, nada é; tudo torna-se ou deixa de ser" (VILLAÇA, 2001, p. 238). Isto posto, coloca-se como fundamental a distinção entre centralidade (processo) e centro (forma espacial). É certo que os centros principais são os espaços dotados de centralidade que representam sua expressão máxima numa determinada aglomeração urbana, o que levou o centro e a centralidade a serem conceitos confundidos por algum tempo. Contudo, a noção de um centro único como forma predominante de articulação urbana foi superada pela prevalência de processos que difundem a centralidade no território e redefinem continuamente seu conceito (SPOSITO, 2010).

O padrão inicial dessa difusão da centralidade no espaço das cidades brasileiras se deu voltado para as classes populares ${ }^{2}$, em face de sua acessibilidade limitada ao centro imposta pela localização periférica de suas moradias. Em função da necessidade de manter relações para sua reprodução social, surgiram em espaços periféricos próximos a um mercado consumidor, concentrações de atividades comerciais e de serviços com considerável nível de complexidade, implicando no surgimento de "subcentros",

\footnotetext{
${ }^{2}$ Villaça afirma que a Praça Saens Peña, no bairro carioca da Tijuca, é "o único caso no país em que um subcentro voltado para as camadas de alta renda surgiu antes que os subcentros populares" (2001, p. 297).
} 
definidos como uma "uma réplica em tamanho menor do centro principal, com o qual concorre em parte sem, entretanto, a ele se igualar" (VILLAÇA, 2001, p. 293). Observa-se que, embora não se equipare ao centro principal em termos de concentração de atividades ou de abrangência de sua área de influência, nestas áreas de centralidade ainda há o potencial para o estabelecimento de relações sociais de maneira mais ampla e complexa tais como no centro, uma vez que se consolidam em meio ao espaço público abrangendo uma população historicamente alijada das áreas dotadas de centralidade.

Portanto, considera-se que a centralidade, enquanto processo, pode se manifestar não apenas no centro, mas também em outros pontos do espaço urbano: "Qualquer ponto pode tornar-se o foco, a convergência, o lugar privilegiado. De sorte que todo o espaço urbano foi, é, e será, concentrado e poli(multi)cêntrico" (LEFEBVRE, 1999, p. 46). Considerando o conceito de poli(multi)centralidade de Lefebvre, Sposito (2010, p. 205) aponta que "é necessário observar que essas diferentes zonas (centros) definem diferentes graus de centralidade. Esses graus articulam-se em função de diferentes níveis de especialização funcional e de segregação socioespacial". Embora sua especialização funcional, ou seu conteúdo possa ser apontado como um fator definidor, numa escala hierárquica de centros, do nível de importância desempenhado por determinado centro, Lefebvre destaca que:

A centralidade não é indiferente ao que ela reúne, ao contrário, pois ela exige um conteúdo. E, no entanto, não importa qual seja esse conteúdo. Amontoamento de objetos e de produtos nos entrepostos, montes de frutas nas praças de mercado, multidões, pessoas caminhando, pilhas de objetos variados, justapostos, superpostos, acumulados, eis o que constitui o urbano. (LEFEBVRE, 1999, p. 110)

Assim, retoma-se a ideia de que o urbano e a centralidade indicam, no seu mais profundo sentido, o espaço por excelência onde as relações sociais se desenvolvem, uma vez que seu conteúdo, apesar de ser imperativo que exista, não corresponde à sua essência, pois é cambiável. No entanto, se as relações sociais são tolhidas pela segregação, pela negação do encontro entre os diferentes, como ocorre nos enclaves 
fortificados $^{3}$ que marcam a metropolização contemporânea, das quais os shopping centers são os exemplos mais nítidos, redefine-se a centralidade, pois ela se torna não apenas menos importante numa hierarquia, como também se torna parcial, fragmentária do ponto de vista social, resguardando somente seu caráter onde se realiza o valor de troca. A esse respeito, Lefebvre considera que:

A diferença ${ }^{4}$ é informante e informada. Ela dá forma, a melhor forma resultando da informação ótima. Quanto à separação e à segregação, elas rompem a informação. Conduzem ao informe. A ordem que constituem é apenas aparente. Só uma ideologia pode contrapô-la à desordem da informação, dos encontros, da centralidade. Só um racionalismo limitado, industrial ou estatista, mutila o urbano, dissociando-o: projetando no terreno sua 'análise espectral', os elementos disjuntos, cuja informação recíproca torna-se impossível. (LEFEBVRE, 1999, p. 124)

Isto posto, considera-se que a (re)estruturação do espaço urbano é resultado e condicionante das diversas relações inter-articuladas por ele centralizadas, desenvolvidas, atualmente, sob o modo específico de produção e organização social capitalistas, com todas as contradições que deste sistema são decorrentes. A centralidade, por sua vez, é um processo com alto poder de estruturação espacial, organizando as relações sociais, fluxos, nós e convergências. Contudo, quando em conjunção com a segregação socioespacial, novas expressões de centralidade produzem um efeito oposto, fragmentando as relações e o próprio espaço urbano, cujos efeitos são intensificados na escala da metrópole. Diferente do centro principal, ou mesmo dos subcentros, assentados sob o espaço público e que supõem o livre acesso ${ }^{5}$ e estabelecimento de relações, as novas formas de centralidade são cada vez mais organizadas no e pelo

\footnotetext{
${ }^{3}$ Enclaves fortificados "são propriedade privada para uso coletivo e enfatizam o valor do privado ao mesmo tempo em que desvalorizam o que é público e aberto na cidade" (CALDEIRA, 2000, p. 258).

${ }^{4}$ Lefebvre (1999) destaca também que "diferença" e "segregação" não são compatíveis, uma vez que a diferença implica em relações, enquanto a segregação e a separação rompem tais relações, além de constituir "uma ordem totalitária que tem por objetivo quebrar a totalidade concreta, espedaçar o urbano" (p. 124).

${ }^{5}$ Em que pese a restrita acessibilidade das classes de renda baixa ao centro, mediante a distância de seus espaços de moradia e às possibilidades reduzidas ou dificultadas de deslocamento, que também constituem fator de segregação socioespacial.
} 
espaço (capital) privado, conferindo peso a grandes equipamentos comerciais e de serviços no papel de estruturadores do espaço urbano (SPOSITO, 2010).

Dessa maneira, questiona-se: de que modo o valor de troca pôde se apropriar estrategicamente da centralidade como forma garantir a reprodução do capital, estruturando, para este fim, o espaço urbano conforme sua lógica? É sobre esta pergunta que o item a seguir pretende refletir.

\section{Centralidade na produção da cidade contemporânea}

Conforme discutido anteriormente, não se pode pensar 0 urbano sem centralidade, processo que se relaciona diretamente com a possibilidade de estabelecimento das diversas relações - econômicas, sociais, políticas - entre grupos sociais, que são a razão de ser da cidade. Dessa forma, considera-se que o usufruto dos espaços públicos dotados de centralidade e a sua apropriação no mais amplo sentido, em que predomine o valor de uso sobre o valor de troca, é imprescindível para a vitalidade do processo.

Mogin explora as possibilidades abertas pelo uso livre do espaço público:

O espaço público é incerto, e o sujeito que ali se arrisca é indeciso; é por isso que ele se esconde por trás de máscaras [...] o flâneur pode se perder na multidão, fundir-se na turba ou então se deparar com o lado noturno da vida pública, [...] também pode, fascinado que é pelos negócios, pelos símbolos e pelas passagens, consumir as mercadorias expostas nas galerias comerciais e nas avenidas. Enfim, o flâneur pode juntar-se à multidão na esperança de mudar o espaço público. (MOGIN, 2008, p. 69)

Nota-se, portanto, que a atividade exercida pelo "flâneur" no espaço público não é orientada para o consumo, embora este também possa ser praticado. Entretanto, o modo como a cidade contemporânea vem sendo produzida indica para, no mínimo, uma mudança no uso dos espaços públicos, que para muitos autores significa o declínio do público em face ao domínio do privado, no qual há um encurtamento da vida pública, das 
possibilidades de encontro, do confronto entre diferentes e, por extensão, da centralidade conforme conceituada por Lefebvre. Caldeira (2000) aponta para a constituição de espaços residenciais segregados que convertem a rotina dos seus habitantes de uma experiência mais aberta e heterogênea em outra, protegida por muros, câmeras e agentes de segurança, negando a existência do outro, do diferente e, assim, favorecendo a homogeneidade.

Ao processo de constituição desses espaços, é possível relacionar essa condição à dominação expressa por Lefebvre através do (pseudo)conceito do "habitat" sobre o "habitar":

O habitat, função simplificada, restringindo o 'ser humano' a alguns atos elementares: comer, dormir, reproduzir-se [...]. Precisamente o habitat, ideologia e prática, rechaçou ou recalcou o habitar na inconsciência. Antes do habitat, o habitar era uma prática milenar, mal expressa, insuficientemente elevada à linguagem e ao conceito, mais ou menos viva ou degradada, mas que permanecia concreta, ou seja, ao mesmo tempo funcional, multifuncional, transfuncional. No reino do habitat, desapareceu do pensamento e deteriorou-se fortemente na prática o que fora o habitar [... 0 habitat foi instaurado pelo alto: aplicação de um espaço global homogêneo e quantitativo obrigando o 'vivido' a encerrarse em caixas, gaiolas, ou 'máquinas de habitar'. (LEFEBVRE, 1999, p. 8081)

Assim como ocorre com o espaço da moradia, o próprio espaço das relações sociais vitais para a centralidade passa a se enquadrar numa lógica semelhante, homogeneizada e dominada pelo consumo, ou pelo valor de troca (capitalizado). Mogin (2008) expõe a mudança nessa lógica ao contrapor as figuras do flâneur, "personagem feminino inseparável da multidão" e do burguês, "homem do interior que capitaliza a mercadoria" (p. 72), apontando para o hábito de exteriorização burguês sempre voltado à interiorização: "O círculo se fecha: a participação no espaço público não tem outro destino senão o consumo. A passagem do privado ao público se paga com um retorno ao privado. O burguês retoma ao seu espaço interior para ali 'expor' o que comprou no exterior" (p. 73). Sob essa lógica, o espaço público se torna somente suporte dos fluxos destinados à reprodução do capital, pelo predomínio do individual sobre o coletivo, do 
valor de troca sobre o valor de uso. Em resumo, a lógica capitalista passa a se apropriar da centralidade para sua estratégia de expansão.

Dessa forma, mesmo a vida pública passa a ser encapsulada pela esfera privada. Caldeira, ao apontar para os exemplos da policentralidade de Los Angeles, resume a característica desses espaços, "onde a maior parte da vida pública acontece em espaços segregados, especializados e fechados, como shoppings, condomínios fechados, centros de entretenimento e parques temáticos de todos os tipos" (CALDEIRA, 2000, p. 333). Ou seja, tudo aquilo que a centralidade reúne de maneira a possibilitar abertura e confronto das diferenças, essas estruturas privadas se apropriam de forma a segregar, homogeneizar comportamentos e evitar o confronto. A centralidade passa a ser, não apenas especializada, como também fragmentada.

Novamente, Lefebvre aponta para o processo em discussão, indicando essa apropriação do privado e do capital:

Não existem lugares de lazer, de festa, de saber, de transmissão oral e escrita, de invenção, de criação, sem centralidade. Mas à medida que em algumas relações de produção e de propriedades não sejam reformadas, a centralidade sucumbirá ao golpe dos que utilizam tais relações em seu proveito. Ela será, no melhor dos casos, "elitista", no pior deles, militar e policial. (LEFEBVRE, 1999, p. 93)

Esse domínio da esfera privada, que atua em várias frentes, como a cultural, por exemplo, impondo seus valores e tendências, além do discurso do medo (CALDEIRA, 2000), também encontra interface na esfera política como forma de garantir os resultados de sua atuação. A esfera política é materializada na produção da cidade a partir da atuação de agentes sociais concretos, que operam a partir de interesses distintos. Na cidade capitalista contemporânea, Marques (2016) identifica esses principais agentes privados, reunidos e agrupados em diferentes "capitais do urbano": capital incorporador, capital dos serviços, capital da construção civil e capital de gestão e consultoria. Destes, é possível considerar que o capital incorporador tem maior potencial para produzir espaços dotados de centralidade e reestruturar o espaço urbano sob a 
lógica capitalista do consumo, pois sua atuação se baseia "mediante a aquisição da terra pelo preço de uso corrente e a venda futura ao preço do uso transformado" (MARQUES, 2016, p. 18). Assim, tais agentes podem influir politicamente na transformação de leis, parâmetros urbanísticos e, inclusive, na definição da execução de obras públicas de infraestrutura que permitam melhor acesso aos seus empreendimentos.

O capital incorporador pode se integrar a outros tipos de capital, como o de serviços públicos, por exemplo. O processo de mudança de uso empreendido pelo capital incorporador também abre brecha para a atuação, ou mesmo a integração, com outro capital do urbano, o especulador ${ }^{6}$, que:

modifica os preços em geral praticados no lugar, a natureza do comércio e serviços e as relações sociais antes existentes. Com a mudança de ocupação e a atração de um novo patamar de renda, o preço geral de venda que se esperava obter a princípio - a partir do qual os demais custos serão descontados - aumenta, ocorrendo assim o que se tem chamado de "valorização imobiliária". É, portanto, o mecanismo de mudança de ocupação do solo por meio de expectativa de futura de valorização que provoca o aumento no preço dos imóveis em determinada região. (HOYLER, 2015, p. 340)

A partir dessas dinâmicas, não interessa somente aos capitais do urbano, por exemplo, no estabelecimento de um novo grande shopping center, que seja garantida sua implantação, mas também que seu entorno social seja transformado de acordo com o tipo de público (classe de renda) que este almeja. Isso favorece a criação de espaços dotados de centralidade próprios à segregação, como de áreas homogeneizadas, destinadas ao uso, circulação e apropriação de um determinado estrato de poder aquisitivo, objetivo que para ser atingido necessita também de ações de repressão para impedir a convivência daqueles que não correspondam ao público ou às práticas

\footnotetext{
${ }^{6}$ Hoyler destaca tratar-se de dois tipos diferentes de agentes: "É, portanto, o mecanismo de mudança de ocupação do solo por meio de expectativa de futura valorização que provoca o aumento no preço dos imóveis em determinada região. Note-se que a incorporação não se confunde com a especulação imobiliária, uma estratégia específica de atuação que consiste em guardar um terreno para valorização futura." Entretanto, confirma que a possibilidade de sua integração: "Se o incorporador especula ou não, depende da estratégia adotada por cada empresa" (HOYLER, 2015, p. 340).
} 
comportamentais esperadas pelo setor privado em seus estabelecimentos e empreendimentos.

Carlos também reforça a inter-relação dos espaços de moradia com os dotados de centralidade nesta estratégia privatista e segregadora:

O espaço urbano tornado mercadoria faz com que seu acesso seja determinado pelo mercado imobiliário; deste primeiro acesso redefinemse outros - por exemplo, o acesso à bens e serviços urbanos, à centralidade -, uma vez que os usos (tanto produtivos quanto improdutivos) submetidos ao valor de troca se articulam a partir do local de moradia. (CARLOS, 2016. p. 99)

Se levada para a escala metropolitana, a redefinição da centralidade baseada na implantação de grandes estruturas privadas comerciais, de serviços e de moradia para as classes de alta renda alcança outros patamares a partir dos quais se expressa a desigualdade socioespacial, pois contribui para replicar em dimensões territoriais maiores o processo de produção dos espaços de moradia das classes de alta e de baixa renda. Não mais produzidos sob a lógica centro-periferia, novos shopping centers, hipermercados, grandes hotéis e condomínios fechados voltados para a alta renda são parte complementar do processo de extensão da metrópole, que disputa espaço com o crescimento de favelas e a expansão de espaços de moradia popular, redefinindo as áreas de centralidade existentes ou induzindo o surgimento de novos subcentros metropolitanos, conforme identificado por Silva (2012) na metrópole de Curitiba na última década.

Esse modelo de segregação forçada entre os espaços de moradia e de consumo das diferentes classes sociais, motivado pela busca de ampliar a reprodução do capital, não ocorre, entretanto, sem conflitos e contradições. Desta forma, a almejada segregação vive sob tensão e sob o risco de romper-se e, neste momento, a convivência e o confronto evitados podem transformar-se em conflito. Tal confronto é especialmente intensificado em cidades marcadas pela desigualdade, como no caso das brasileiras, onde espaços que simbolizam a atual fase do capitalismo, como os anteriormente 
apresentados, se colocam lado a lado com espaços precários, informais e produzidos por lógicas e relações que, embora interajam com as primeiras, diferem delas, e, pois, expressam não apenas a dificuldade de se inserir naquela lógica de produção do espaço, mas também a resistência de seus moradores a este modelo.

No tocante ao setor terciário, que congrega importantes atividades características de centros e subcentros, esta desigualdade se expressa, no caso brasileiro, por "uma estrutura de serviços muito diversificada numa ponta, quando ligada aos estratos de altas rendas, a rigor mais ostensivamente perdulários que sofisticados; noutra, extremamente primitiva, ligada ao consumo dos estratos pobres" (OLIVEIRA, 2003, p. 133). No espírito dessa modernidade incompleta, na qual importa "parecer moderno, mais do que ser moderno", pois a modernidade está "mais no âmbito do ser visto do que no do viver" (MARTINS, 2008, p. 33), os símbolos de diferenciação entre classes encontram-se borrados pela profusão de objetos e símbolos do capital (CALDEIRA, 2000; MARTINS, 2008).

Resta, então, às classes altas, recorrer a espaços de circulação controlada que "servem para assegurar que a distinção e a separação ainda são possíveis em público. Sinais de distância social são substituídos por muros concretos" (CALDEIRA, 2000, p. 325). Nessa lógica, os enclaves das novas expressões de centralidade destinadas a segregar estratos sociais são complementares aos enclaves residenciais, ambos portadores do status social e dispersos por toda a metrópole, que, ao interpor muros entre sua realidade e a realidade dos diferentes, ajudam a apagar - se não literalmente, ao menos visualmente - a existência do outro para estas classes.

\section{O direito à cidade como direito à centralidade}

A alternativa a essa realidade desigual, ao sistema que converte até mesmo as relações sociais em alvo da lógica mercantil, dos "níveis pretensamente superiores da prática social" (LEFEBVRE, 1999, p. 96) está no que Lefebvre indica, através da leitura da obra de Marx, como a reinversão do mundo invertido, cuja obtenção só é possível pela mobilização e resistência. Considerando a obra de Harvey, que chama a reivindicar a 
cidade para a luta anticapitalista, nota-se o papel fundamental que as cidades possuem para o embate que visa a conversão da vida cotidiana alienada em outra, na qual os sujeitos e grupos sociais possam construir relações sociais e produtivas segundo outra lógica, que não a do valor de troca do capital. Para o autor, os efeitos da exploração capitalista na cidade contemporânea "são basicamente sentidos no local onde se vive, e não na fábrica" (HARVEY, 2014, p. 231), o que leva à questão: "Por que, então, não se concentrar na cidade, em vez de na fábrica, como lugar por excelência da produção da mais-valia?" (HARVEY, 2014, p. 232).

Essa noção vai de encontro ao discutido anteriormente; a exploração se dá a partir das próprias dinâmicas de produção do espaço urbano capitalista, na segregação socioespacial, na fragmentação do espaço urbano, numa estruturação espacial mais complexa e fractal. É nesse entendimento que os movimentos sociais urbanos passam a ter um papel de grande importância, divergindo da leitura marxista clássica que coloca o gérmen dos movimentos sociais de resistência e luta no espaço da fábrica, uma vez que "a dinâmica da exploração de classe não se restringe ao local de trabalho" (HARVEY, 2014, p. 230). Para um movimento nesse sentido, "em geral, é necessário uma ação política organizada para resistir aos muros ou para desmanchar padrões de segregação. Na vida cotidiana, é difícil contestar os muros e rituais de suspeição e humilhação" (CALDEIRA, 2000, p. 302).

A chave para avançar na luta e resistência a essa realidade, que escapa à alienação cotidiana dos indivíduos e grupos, encontra-se em subverter o "domínio da lógica instrumental-abstrata [...] que segue o 'modelo' fundamental da abstração dessas sociedades que é o da mercadoria, da instrumentalização e das estratégias" sobre a "lógica comunicativa-concreta [...] que se encontra naquelas relações entre os homens caracterizados pelo reconhecimento mútuo, a compreensão e expressão de uma dialética entre os sujeitos e seus objetos (como valor de uso)" (RANDOLPH, 2015, p. 110).

Torna-se visível, portanto, que a centralidade como possibilidade de encontro, de ativa constituição de relações que constroem e reconstroem o urbano, de questionamento, de comunicação e ação política, enfim, a centralidade entendida no seu mais amplo e irrestrito sentido, não reduzida à lógica do domínio do valor de troca, é um 
fator fundamental para a gênese de movimentos sociais, pois possibilita a interação necessária à construção da lógica comunicativa-concreta:

A centralidade como característica do urbano se revela enquanto potencialidade de aglomeração e sociabilidade entre os indivíduos que partilham da mesma realidade. [...] A partilha do mesmo espaço e a identificação do outro como semelhante na exploração pelo capital pode gerar a mobilização necessária à constituição do movimento social. (PEREIRA, 2012, p. 33)

Por isso, entende-se que o direito à cidade está em algo mais que o direito ao seu acesso, conforme explica Harvey:

O direito à cidade deve ser entendido não como um direito ao que já existe, mas como um direito de reconstruir e recriar a cidade como um corpo político socialista com uma imagem totalmente distinta: que erradique a pobreza e a desigualdade social e cure as feridas da desastrosa degradação ambiental. (HARVEY, 2014, p. 247)

Assim, a luta pelo direito à cidade se confunde e se une ao direito à centralidade, pois no último reside a condição para uma construção e transformação ativa da sociedade e pela sociedade. Nessa luta pelo direito à centralidade está o direito a residir em espaços dotados de centralidade, desmanchando a fragmentação do espaço urbano, à sua apropriação, entendida como o livre acesso à centralidade como força de interação e mobilização social, não submetida às práticas de consumo capitalistas. O direito à centralidade corresponde, portanto, ao caminho de transformação da sociedade fragmentada e segregada em outra, onde as relações entre os diferentes possam existir, reconfigurando sua própria condição.

\section{Conclusão}

Os conceitos e relações estabelecidos contribuem para entender de maneira mais ampla, e numa perspectiva dialética, a função da centralidade no processo de 
estruturação do espaço urbano na produção da cidade e da metrópole contemporânea. Além disso, propiciam refletir acerca da apropriação da centralidade pelo capital visando sua reprodução, a preponderância do valor de troca sobre o valor de uso e a conversão da vida pública em fragmentos privatizados. Nesta perspectiva, o reconhecimento e a promoção da centralidade como um direito dos cidadãos contribui para que a análise das dinâmicas que caracterizam o processo de difusão da centralidade no território, expressa por diferentes formas espaciais, contenha em si uma crítica mais apurada dos seus agentes promotores e de suas estratégias implícitas.

A reflexão permitiu entender também que a luta pelo direito à cidade não pode ser dissociada do direito à centralidade, pois garantir esse direito, ao livre encontro, à integração dos espaços dos indivíduos e grupos sociais diferentes significa a possibilidade de superar a segregação socioespacial e a desigualdade, características marcantes da produção da cidade contemporânea. Dessa maneira, ficam restabelecidas as bases para o entendimento da centralidade, avançando da sua caracterização objetiva, da aglomeração de atividades econômicas, nó de fluxos de deslocamento de pessoas e produtos no meio urbano, enfim, de características que tendem a uma quantificação do processo, para um viés que visa qualificar estes espaços como essenciais para a vida nas cidades. 


\section{Referências}

CALDEIRA, Teresa Pires do Rio. Cidade de muros: crime segregação e cidadania em São Paulo. São Paulo: Editora 34: EDUSP, 2000.

CARLOS, Ana Fani Alessandri. A prática espacial urbana como segregação e o "direito à cidade" como horizonte utópico. In: VASCONCELOS, Pedro de Almeida; CORRÊA, Roberto Lobato; PINTAUDI, Silvana Maria. A cidade contemporânea: segregação espacial. São Paulo: Contexto, 2016. p. 95-110.

CASTELLS, Manuel. A questão Urbana. Rio de Janeiro: Paz e Terra, $3^{\text {a }}$ ed., 1983

CORRÊA, Roberto Lobato. O espaço urbano. São Paulo: Ática, 1989.

HARVEY, David. Reivindicando a cidade para a luta anticapitalista. In: HARVEY, David. Cidades rebeldes: do direito à cidade para a luta anticapitalista. São Paulo: Martins Fontes, 2014. p. 209-272.

HOYLER, Telma. Qual o lugar das cidades no mercado imobiliário financeirizado? Revisitando conceitos críticos a partir do caso brasileiro. Oculum Ensaios, Campinas, n. 12, jul.,/dez. 2015. p. 335-344.

LEFEBVRE, Henri. A Revolução Urbana. Tradução de MARTINS, S. Belo Horizonte: Ed. UFMG, 1999.

MARQUES, Eduardo. De volta aos capitais para melhor entender as políticas urbanas. Novos Estudos CEBRAP, São Paulo, n. 105, jul. 2016. p. 14-33.

MARTINS, José de Souza. A sociabilidade do homem simples. São Paulo: Editora Contexto, 2008.

MOGIN, Olivier. A experiência pública ou a cidade colocada em cena. In: MOGIN, Olivier. A condição urbana. A cidade na era da globalização. São Paulo: Estação Liberdade, 2008. p. 61-83.

OLIVEIRA, Francisco de. O ornitorrinco. In: OLIVEIRA, Francisco de Crítica à razão dualista o ornitorrinco. São Paulo. Boitempo, 2003. p. 121-150.

RANDOLPH, Rainer. A origem estrutural da subversão em sociedades capitalistas contemporâneas, suas práticas baseadas na vivência cotidiana e um novo paradigma de planejamento. In: COSTA, Geraldo Magela; COSTA, Heloísa Soares de Moura; MONTEMÓR, Roberto Luís de Melo (Eds.). Teorias e práticas urbanas: condições para a sociedade urbana. Belo Horizonte: C/Arte, 2015. p. 103-127. 
PEREIRA, Stefanie Berenschot. Centralidade urbana e lutas sociais: a Associação dos Favelados de Piracicaba. 2012. 93 f. Dissertação (Mestrado em Geografia) - Universidade Estadual Paulista -Instituto de Geociências e Ciências Exatas. Rio Claro, 2012.

SILVA, Madianita Nunes da. A dinâmica de produção dos espaços informais de moradia e o processo de metropolização em Curitiba. 2012, 259 f. Tese (Doutorado em Geografia) Universidade Federal do Paraná - Setor de Ciências da Terra. Curitiba, 2012.

SPOSITO, Maria Encarnação Beltrão. O centro e as formas de expressão da centralidade urbana. Revista de Geografia. Universidade Estadual Paulista. São Paulo, 1991 v.10. p. 1-18

SPOSITO, Maria Encarnação Beltrão. Multi(poli)centralidade urbana. In: SPOSITO, Eliseu Savério; SANT'ANNA NETO, João Lima (Orgs.) Uma geografia em movimento. São Paulo: Expressão Popular, 2010. p. 199-228.

VILLAÇA, Flavio José Magalhães. Espaço intra-urbano no Brasil. São Paulo: Studio Nobel, 2001.

Recebido em: 20/03/2018 Aprovado 22/08/2018

Universidade do Estado de Santa Catarina - UDESC Centro de Ciências Humanas e da Educação - FAED

Revista PerCursos Volume 19 - Número 40 - Ano 2018 revistapercursos@gmail.com 